\title{
ESTUDO SOBRE A COMPOSIÇĀO DOS REGISTROS DE ENFERMAGEM PELOS ACADÊMICOS DE ENFERMAGEM EM UM HOSPITAL DE ENSINO.
}

\author{
Maria da Graça Oliveira Crossetti * \\ Beatriz Ferreira Waldmann **
}

\begin{abstract}
RESUMO - O presente trabalho consta de um estudo exploratório descritivo em que são analisados os registros de enfermagem, elaborados pelos acadêmicos de enfermagem em seu aspecto estrutural, visando classificá-los de acordo com os critérios propostos por ANGERAMI et alii para a composição dos mesmos, e também propor um modelo para a elaboração da evolução de enfermagem centrada na avaliação do paciente. Para a coleta de dados foram elaborados três instrumentos e um codificador de análise que compreende a descrição dos elementos de composição dos registros de enfermagem. Os dados foram coletados junto aos 53 acadêmicos de enfermagem do 7 ㅇ semestre do curso de graduação. Concluiu-se neste estudo que $96,15 \%$ e $77,77 \%$ sujeitos dos grupos A e B respectivamente, percebem seus registros com bons no início e ao término do semestre. Quanto aos critérios de classificação, os registros analisados apresentaram-se em ambos os grupos: quanto ao número de sinais: compostos; à linguagem: especializada, ao estilo claro; coesão: uniforme densidade: sintéticos e quanto ao propósito no grupo A: persuasivos e no grupo B, dissuasivos.
\end{abstract}

\begin{abstract}
This is a descriptive study which analyses nursing registries made by nursing students. It classifies them according to ANGERAMI et alii criteria and suggests a model of nursing centralized on patient's evaluation. The authors elaborated three instruments and one code system describing the components of the registries. Data have been collected among students attending 7 th semester of the graduation course in the beginning and in the end of the semester. They concluded that $96,15 \%$ of the students of group $A$ and $77,77 \%$ of group $B$ think they make good registries. About the criteria of classification the registers analised have been seen in both of the groups, about the $n$ o of signs: compound; the language: specialized; style: clear; cohesion: uniform;

group A, persuasive and in the group B dissuasive.
\end{abstract}

\section{INTRODUÇĀO}

Dentre de muitas habilidades que o enfermeiro deve dominar para efetivar plenamente o seu objetivo de prestar assistência integral ao indivíduo no seu contexto bio-psico-social, temos a comunicação interpessoal como um componente essencial para o sucesso de sua atuação.

Sendo a comunicação um processo social básico, faz-se necessário estudá-la como elemento vital no relacionamento dos indivíduos. Para que ela exista é preciso tornar claro quem, o porquê e com quem esse processo está se realizando. Os seus comportamentos são constiturdos de: mensagens produzidas o que as pessoas procuram transmitir o estilo, a forma de tratamento de suas mensagens; os meios de comunicação, os canais usados para atingir os ouvintes ou os leitores. Estes aspectos comprendem os elementos básicos da comunicação que são: a fonte, o codificador, a mensagem, o canal e o receptor.

O sucesso ou fracasso deste processo relacionado à interação destes elementos. Alguns obstáculos dificultam ou impedem o receptor compreender a mensagem emițida pela fonte, quais sejam: limitação de sua capacidade de recebê-la, distração, presunção não enunciada, incompatibilidade de planos, influência de me-

* Profeceos Adjunto do Deparmento de Enfermagem MÉdico-Cirúrgica da Escola de Enfermagem da UFRGS.

** Professora Auxiliar de Ensino do Deperenmento de Enfermagem Médico-Cirírgica da Escola de Enfermagem da UFRGS. 
canismos inconscientes ou parcialmente conscientes, apresentaçāo confusa e ausência de recursos de comunicaçåo, BERLO4, PARRY'20.

No hospital, o processo de comunicação constitui in avalisço e controle da assistência cuja base situa-se no relscionamento interpessoal da equipe de saude, segundo DANIEL", CUNHA ${ }^{10}$.

Da efetividade do processo de comunicação depende a otimização quantitativa e qualitativa do cuidado prestado, segundo FAVERO et alii' ${ }^{3}$, CUNHA $^{10}$, pois E através dela que os elementos da equipe tomam ciência das açōes e dos objetivos destes na resolução dos problemas dos pacientes. A maneira como o conteúdo da mensagem $\varepsilon$ descrito $\varepsilon$ um aspecto a ser considerado no processo da comunicação. Portanto, é importante considerar-se: o emissor emprega linguagem clara e precisa e o receptor pode compreende-la, o nível de interpretação necessário alcança o conteúdo da mensagem; se há disponibilidade entre o que se diz e o que se quer dizer; se as mensagens não são antagônicas e se há a necessidade de repetir a mensagem em outras palavras ou forma de comunicação, segundo TRAVELBEE ${ }^{22}$.

No exercício da assistência de enfermagem o processo de comunicação poderá ser prejudicado quando a fonte emite mensagem cujos conteudos divergem da expectativa do receptor.

O canal de comunicação na enfermagem são as anotaçes que configuram os registros de todos os dados do paciente. Constituem um veŕculo de comunicação entre os membros da equipe e os demais profissionais de saúde. Instrumento imprescindível para a avaliação da assistência de enfermagem porque permite acompanhar a evolução do cuidado e do tratamento do paciente, favorece a educação de médicos, de enfermeiros e de outros profissionais e constituem um documento legal e fonte de pesquisa, segundo ANGERAMI et alii'

$A$ inexistência de uniformidades e de padröes dos registros de enfermagem caracterizando-os como incosistentes e empiricos, têm sido objeto de preocupações e de estudo dos enfermeiros docentes e assistenciais, como demonstram os estudos de ANGERAMI et alii', 2, ', CUNHA ${ }^{10}$, FERNANDES et alii'4, DUARTE $^{12}$, FRAGA ${ }^{15}$.

Segundo $\operatorname{COSTA}^{\circ}$, os registros devem representar um conjunto completo sistematicamente organizado e claro, atender a problemaação-resultado. Devem ser objetivos sem serem incensiveis, completos sem observar uma quantidade exagerada de tempo com descriçōes funcionais, evitando-se a fragmentaģă dos dados.

As anotaçes devem contr fatos e opiniōes, nāo somente uma lista de dedos e nsoo se fixarem em manifestações básicas patológicas. Segundo ANGERAMI et aliiis e para NÓBRE$\mathrm{GA}^{18}$, devem ser: descritivas e nâo interpretativas, corretas, objetivas e completas, evitando qualquer afirmação diagnóstica ou interpretativa de seus achados. Devem registrar as condiçōes do paciente e sua atividade. Transmitirem informaçōes acerca do paciente, prover uma base de integração e continuidade ao plano total de cuidado, mostrarem que as prescrições foram cumpridas com relação à medicação e ao tratamento e observados os resultados, registrarem a proporção e o tipo do progresso alcançado pelo paciente, assim como ajudá-lo a enfrentar os problemas na medida em que ele deseja e aceita.

ANGERAMI et alii $^{2}$ em estudo recente sobre a composição das anotaçōes de enfermagem, pretendeu verificar se as mesmas correspondiam às expectativas da equipe médica, tendo constatado que $55,3 \%$ dos entrevistados afirmaram que as anotaçōes de enfermagem foram positivas porque nelas "encontram informações complementares sobre a evolução clínica dos pacientes; verificaram o cumprimento das ordens médicas; as informaçōes sāo detalhadas e só informam sobre necessidades fisiologicas". Entretanto, da populaçāo entrevistada, 34,2\% responderam que as anotações de enfermagem não atingem os objetivos porque "as informações são inúteis, carecem de objetividade, são superficiais, extensas, incompletas, irreais, compostas de termos dúbios, nảo têm ordem lógica e deixam muito a desejar". As duas afirmações realizadas pela populaçåo entrevistada denunciam uma forte relação com a forma estrutural e com os elementos que caracterizam a composição das anotações de enfermagem.

$\mathrm{Se}$ os registros elaborados pelos enfermeiros fossem completos, exatos e pertinentes em relação aos problemas de enfermagem, muitos se constituiriam numa fonte confiável para o controle da qualidade da assistência prestada ao paciente, e ao controle do ensino oferecido na graduação.

$O$ ensino de um planejamento assistencial cuidadoso e a correta elaboração de registros nos cursos de graduação em enfermagem $\dot{e}$ fator singular no desenvolvimento da profissão, pois retratará o perfil do futuro profissional, sendo fundamental o papel do educador na conscientização do aluno sobre a importância da sistematização da assistência, conforme preconiza PAIM $^{10}$ e CHACCUR ${ }^{7}$.

Cada vez mais se faz necessário por parte dos docentes a avaliação sistemática e continua da qualidade do ensino que $\boldsymbol{\epsilon}$ oferecido ao aluno do Curso de Rnfermagum, sujeito e objeto de 
nossa ação.

A partir da nossa experiência como dọcentes da graduação, acompanhando e assessorando os estágios dos acadêmicos do sétimo semestre, na disciplina da Assistência de Enfermagem ao Adulto III, cuja característica básica é assistência ao adulto hospitalizado em estado crítico, surgiu a proposta de avaliarmos os registros de enfermagem elaborados pelos alunos durante este período, considerando as dificuldades manifestadas e percebidas para a elaboração dos mesmos, quanto ao o quê e como deveriam registrar.

Frente ao exposto, o presente estudo objetivou analisar os registros de enfermagem elaborados pelos acadêmicos de enfermagem em seu aspecto estrutural, visando classificá-los de acordo com os critérios propostos por ANGERAMI et alii $^{2}$ para a composição, dos mesmos, verificar a percepção dos alunos acerca de seus registros.

\section{METODOLOGIA}

Trata-se de um estudo exploratório descritivo, que teve como campo de pesquisa as unidades de internação médica, cirúrgica e tratamento intensivo clínico cirúrgico de um hospital de ensino.

A amostra compreendeu todos os alunos do 70 semestre do curso de graduação em enfermagem que estavam matriculados na disciplina de Assistência de Enfermagem ao Adulto III. Este foi dividido em dois grupos. O grupo A que compreendeu alunos que receberam orientação formal sobre registros de enfermagem e o grupo B que não compartilhou desta orientação.

Para a coleta de dados foram elaborados três instrumentos, um formulário e dois questionários, que compreendem itens formulados para alcançarem objetivos traçados para o presente estudo e que foram previamente testados. Estes instrumentos foram aplicados no início e ao término do semestre em questão.

Para a análise dos registros de enfermagem dos acadêmicos, elaboramos um codificador, que compreende a descrição de seus elementos de composição, propostos por ANGERAMI et alii $^{2}$.

\section{ANÁLISE E DISCUSSĀO DOS RESULTADOS}

Os registros de enfermagem são verdadeiros espelhos que refletem a qualidade da assistência prestada ao paciente, pois deve traduzir o planejamento, a execução e a avaliação da mesma.

Neste contexto, cabe salientar a importância de ensinar como elaborar os registros de enfermagem para, que os alunos, futuros profissio- nais de enfermagem, dominem os instrumentos básicos necessários ao planejam nto da assistencia e adquiram a consciência profissional, de que o enfermeiro faz parte de uma equipe e, por conseguinte, é imprencidível registrarem o que implementam, bem como as respostas dos pacientes a esta terapêutica.

Os registros devem representar um conjunto completo de dados sistematicamente organizados e claros atendendo ao problema-ação-resultado. Devem ser objetivos, sem ter insensíveis, completos evitando uma perda exagerada de tempo com descrições funcionais e fragmentação dos dados, conforme alude COSTA ${ }^{8}$.

No presente estudo em que procuramos analisar como se apresentavam os registros de enfermagem elaborados pelos dois grupos de alunos do curso de enfermagem, constatamos que estes se classificam como "Composta", "Clara" "ao número de sinais e estilo".

Acredita-se que esta a] esentação prenda-se ao fato de que a amostra de sujeitos do penúltimo semestre do curso e se espera que os mesmos já detenham conhecimentos básicos e cientificos que os conduzem à elaboração de registros com estas características. A contraposto evidencia-se que $25,92 \%$ e $18,52 \%$ dos alunos integrantes do Grupo B apresentaram registros "Confusos" no início e no final do semestre. Apesar da orientação do professor, talvez este fato esteja associado à falta dos conhecimentos básicos sobre os princípios que orientam a elaboração dos registros de enfermagem, associado ao desconhecimento da assistência de enfermagem específica do paciente objeto de estudo da disciplina de Assistência de Enfermagem ao Adulto III. Por vezes o aluno não integra os instrumentos básicos necessários ao exercício competente de sua prática comprometendo assim a qualidade das anotações por ele efetuadas.

No mesmo cenário percebemos a questão da "Coesão" dos registros dos alunos. As evoluções do tipo "fragmentadas" estiveram presentes em ambos os grupos no início, nos grupos A e B, e no término do semestre somente no grupo $B$, em $18,51 \%$ dos sujeitos. Neste contexto percebe-se a eficácia e a eficiência de um ensino sistematizado sobre as anotaçōes, e consequentemente a qualidade da atenção de enfermagem prestada à comunidade. Na fragmentação dos registros percebe-se que não há articulação, nem relação destes dados. Acredita-se que este critério de classificação esteja diretamente relacionado à integração de conhecimentos teóricos e práticas, a partir da evolução de princípios cientrficos, das ciências básicas que embasam a prática de enfermagem. Aspecto este ausente na maioria de nossos alunos, ou 
por que não têm interesse e motivação em aprofundar sua aprendizagem ou por que não lhes é dado a oportunidade de reflexão e análise do que exercitam, devido a características do docente que os acompanha, ou à carência de tempo disponível para fazê-lo.

Quanto à "Linguagem" observamos que os integrantes dos grupos A e B apresentaram mudança de comportamento no decorrer do curso da disciplina, apesar de reforçarem a necessidade de estudarem termos técnicos.

As evoluções densas e sintéticas com o propósito dissuasivo estão diretamente relacionados entre si. $\mathrm{O}$ aluno de enfermagem que assim procede em seus registros, parece-nos que carece inicialmente do conhecimento da assistência do paciente que o leva a implementar cuidados meramente rotineiros, sem objetivos previamente estabelecidos. Este fato o leva a fazer anotações telegráficas e sem argumentos cientificos que justifique suas ações. Esta característica parece-nos que também está relacionada ao fator medo de registrar, devido à insegurança ou até mesmo ao medo de compromenter-se com o que escreve. Com frequência observa-se que não é dado ao aluno o direito de errar, levando-o assim a rever um conteúdo teórico sem profundidade, que atende a diluir-se através dos tempos. $\mathrm{E}$ quando profissionais, por não terem o domínio do método, e quem sabe, pelo receio de se exporem podem até planejar a assistência de seus pacientes, mas de forma assistemática e sem registro. Alude-se ainda que a sinteticidade dos dados relaciona-se com a dificuldade na habilidade de avaliar o paciente, através da sistematização da assistência.

Os resultados mostram que o fator orientação sobre registros de enfermagem, antes de iniciar o curso de disciplina de assistência de enfermagem, não foi determinante na mudança de comportamentos significativos, entre os grupos A e B. Acreditamos que este dado este ja relacionado ao fato de que o professor que atua nesta disciplina deverá ter a consciência do valor científico e legal dos registros de enfermagem e o transfira para seus alunos.

Mesmo diante destes resultados acreditamos que o ensino sistematizado dos registros de enfermagem deva ser ministrado de maneira formal aos alunos do curso de graduação em enfermagem, até porque este conteúdo integra a metodologia cientifica em enfermagem.

O ensino dos planos de cuidados nos cursos de graduação em enfermagem é fator singular no desenvolvimento da profissão, pois retratará o perfil do futuro profissional, sendo fundamental o papel do educador na conscientização do aluno sobre a importância da sistematização da assistência, segundo CAR et alii $^{6}$ e CHAC-

\section{CUR ${ }^{7}$.}

O professor é o modelo seguido pelos alunos para a elaboração dos registros de enfermagem conforme resultados deste estudo. Seria "lamentável" se o dado fosse outro. Estudos vêm demonstrando o crescente número de docentes que procuram aprimorar-se através da realização de cursos de pós-graduação e outros, visando assim, a competência continuada e o exercício da função de docência com qualificação. Esta é uma das características dos docentes da disciplina de Assistência de Enfermagem ao Adulto III.

O professor detentor das experiências teórica e prática transmite com cientificidade e com base na realidade, os conhecimentos ao alunado, o que auxilia sobremaneira na sua formação.

A dicotomia entre o acervo de conhecimentos científicos disponíveis e o seu uso na prática de enfermagem é marcante. porquanto a integração docente-assistencial nas instituiçōes de saúde para a ser a maneira de cristalizar o exercício de uma enfermagem adequada à realidade dos que a praticam e recebem. É indispensável que o campo de prática seja modelo de aprendizagem, já que ele orienta a formação dos novos profissionais, elementos da mudança na sistemática, conforme FERNANDES et alii'4, SANCHEZ et aliii ${ }^{21}$. Parece ser este um aspecto de total desconhecimento por parte dos enfermeiros que atuam no campo em que os alunos fazem suas práticas, pois apenas 2,50 (2) sujeitos seguiram como modelo os registros dos mesmos.

Estudo realizado sobre a análise da estrutura da prescrição de enfermagem, na instituição que foi campo de pesquisa para o presente estudo, concluiu, entre outras constatações, que os registros através das prescrições e evoluções de enfermagem eram efetuadas sem uma sistematização e sem adequação aos problemas de enfermagem dos pacientes, além do que eram efetuadas significativamente tendo por base registros de rotina, desqualificando a assistência de enfermagem como regular e descaracterizando-a como holística, de acordo com a percepção de CROSSETTI ${ }^{\circ}$.

De posse desta informação e análise in loco infere-se que os acadêmicos tenham feito uma seleção natural do que consumir ou de quem modelar-se.

A "Bibliografia" representa o segundo referencial seguido pelos alunos que elaboraram os registros de enfermagem, $30 \%$ (24). Este referencial é farto nas publicações sobre enfermagem básica e especializada. $O$ aluno tem amplo acesso e lhe é exigido consultar por ocasião de ensinos teóricos e práticos, apesar de pouco 
apofindarem os conhecimentos acerca dos princlpios que norteiam a elaboração dos registros de enfermagem.

A desmotivação do aluno no campo de estagio, o desconhecimento da estrutura das anotaçōes de enfermagem, a desilusão com a profissāo, a ineficiência e ineficaz supervisōes docente e a insegurança podem representar os fatores determinantes para que 2,50 (2) dos acadêmicos que fizeram parte da amostra deste estudo façam seus registros "SEM MODELO".

A segurança em desempenharmos quaisquer atividades em nossas vidas é proporcional a grau de conhecimento e domínio do que vamos exercitar. Na prática de enfermagem esta regra se faz presente no seu dia-a-dia. Se determos o saber teórico e prático do processo de trabalho da enfermagem, com o domínio dos instrumentos que o integra, garantimos uma assistencia qualificada àqueles que precisam reverter suas necessidades básicas em desequilíbrio.

Verificamos um aumento do número de alunos do Grupo B que expressam ter segurança na elaboração de seus registros ao final do semestre, embora façam parte da amostra que não recebeu orientação formal sobre registros. Inferimos que houve uma importante atuação do professor em campo de estágio que incentivou e estimulou a prática sistematizada da evolução de enfermagem a partir do planejamento, da execuçảo e da avaliação da assistência prestada.

A importância dos registros para o planejamento cuidados $\rho$ assim como a execução, a supervisão e a avaliação das açōes de enfermagem visando o aprimoramento da assistência prestada ao paciente têm sido ressaltadas por CAL DAS et alii ${ }^{5}$, CUNHA ${ }^{10}$.

O ensino de um planejamento assistencial cuidadoso e a correta elaboração de registros nos cursos de graduação em enfermagem é fator singular no desenvolvimento da profissão. Ele retratará o perfil do futuro profissional na sua conscientização sobre a importância da sistematização da assistência, conforme preconiza PAIM ${ }^{10}$.

Mesmo os alunos de ambos os grupos tendo respondido que se sentiam seguros para a elaboraçảo dos seus registros, observamos na prática de estágio e mesmo durante a aula teórica que estes alunos apresentavam dificuldades na elaboração dos seus registros de enfermagem. Atribuimos este fato, em 10 lugar, ao seu desconhecimento quanto à forma estrutural e aos elementos que caracterizam a composição dos mesmos. ANGERAMI et alii $^{2}$ citam que as anotaçōes de enfermagem devem ter as seguintes características: ser composta, clara, especializada, uniforme, detalbada e persuasiva. Em 2 o lu- gar, relacionamos a falta de domínio por parte dos alunos devido ao desconhecimento da assistência de enfermagem, ou sèja, da aplicação ào processo de enfermagem na prática assistencial. Conforme evidencia este estudo, as principais dificuldades apontadas para a elaboração dos registros de enfermagem citadas pelos alunos com e sem orientação, encontram-se na "avaliação do paciente" no domínio das fases do Processo de Enfermagem, no "desconhecimento da terminologia cientifica".

Ao término do semestre percebeu-se que houve aprimoramento dos registros dos sujeitos de ambos os grupos conforme os achados nesta pesquisa. Entretanto, salientamos que 7,40 (2) alunos do grupo B terminaram o semestre ainda inseguros na elaboração de seus registros de enfermagem, assim como 3,85 (01) aluno do grupo A. Da mesma forma que 3,85 (1) e 11,12 (3) sujeitos do grupo A e B, respectivamente, concluiram a disciplina de Assistência ao Adulto III classificando seus registros como "Regular". Isto reforça nosso entendimento de que, a sistematização dos registros de enfermagem deve ser exercitada ao longo da formação do aluno e, que não será em apenas um semestre, no final da carreira, recebendo orientação mais formal, que deterá todos os princípios que orientam este instrumento de enfermagem. Mesmo assim deverá manter uma competência continuada.

Comparando os resultados deste estudo podemos conferir que os alunos demonstraram evolução positiva na elaboração dos seus registros, embora esperássemos que o Grupo A apresentaria outro resultado. Já os resultados dos alunos do Grupo B foram coerentes diante da evidência da evolução positiva na aprendizagem dos mesmos ao longo do semestre.

O processo de enfermagem é o registro essencial à qualidade do cuidado e à manutenção de um elevado padrão de assistệncia prestada ao cliente, assim como à segurança deste. Favorece o inter-relacionamento entre os familiares do cliente e a equipe de enfermagem, além do que, proporciona uma estrutura, mais do que um meio, para avaliar a contribuição econômica da enfermagem na assistência integral ao paciente e dá autonomia ao trabalho do enfermeiro, segundo DANIEL ${ }^{11}$, CROSSETTI ${ }^{9}$, LUCKESI et alii $^{17}$.

Embora o uso do método científico seja válido ao desenvolvimento da enfermagem, não é visto como a essência da mesma, para DANIEL ${ }^{11}$, pois ainda não constitui um procedimento usado por todos os profissionais da assistência. As barreiras de ordem técnica e administrativas, fazem com que seja desacreditado pelos enfermeiros quanto à exequibilidade $\mathbf{e}$ 
vantagens que oferece.

Estudos vêm demonstrando a existência de fatores impeditivos na prática do processo de enfermagem, pelos enfermeiros, tais como falta de tempo, desconhecimento da metodologia, dicotomia entre o ensino e serviço, o uso abusivo da intuição pelos enfermeiros para resolver os problemas, entre outros. Neste estudo, os alunos evidenciaram terem problemas para a elaboração dos registros de enfermagem, instrumentos este presente em todas as etapas do processo de enfermagem. $O$ ensino e a prática do processo de enfermagem estão essencialmente relacionados com o marco teórico que fundamenta esta metodologia, o que implica em mudanças nos marcos conceituais dos currículos das escolas de enfermagem. Estes deverão ser experimentados pelo discente, desde o início de sua formação, permitindo ao aluno uma melhor compreensão dos objetivos desta metodologia, evitando entendê-la como uma prática isolada, centrada nas necessidades da equipe de saúde e da instituição desvinculada da assistência ao cliente.

Dificuldades na "redação dos registros" é o problema mais citados pelos acadêmicos que fizeram parte deste estudo. Tanto no Grupo A como no Grupo B. Se reunidas todas as dificuldades apresentadas pelos alunos, as mesmas compreenderiam uma grande área problemática qual seja o desconhecimento da assistência e da metodologia científica aplicada à enfermagem.

Esta situação conduz o aluno ao exercício de registros ineficientes e ineficazes, que com frequência esconde-se atrás da justificativa "falta de tempo" para a realização das suas funções no campo de prática, fato este que já faz parte dos mitos da enfermagem, de acordo com nossa percepção. Neste contexto, é que acreditamos ser valiosa a intervenção do professor através da orientação e supervisão direta dos acadêmicos. Asserção que vem ao encontro dos resultados obtidos.

Constatou-se ainda neste estudo a mudança de percepção dos alunos do Grupo A e do Grupo $\mathrm{B}$, quanto ao tipo de dificuldades que apresentam para elaborarem os registros de enfermagem. As mesmas se fazem presentes, com maior frequência no início do semestre quando ainda não tínham recebido orientação formal (Grupo A), ou não formal (Grupo B) sobre como elaborar este instrumento de comunicação.

Os referenciais teóricos de WEED ${ }^{23}$, HOR$\mathrm{TA}^{18}$, PAIM ${ }^{19}$, ANGERAMI et aliii $^{2}$ que orientam a elaboração dos registros de enfermagem devem serem consumidos pelos professores e scu alunado tendo em vista a atenção qualificada e holística. Da mesma forma, o consumo daqueles que orientam a acrescem conhecimentos acerca da assistência de enfermagem. Neste contexto, recomendamos o uso da metodologia, estudos de casos pelos alunos nos campos de estágio, o que promoverá a integração da teoria às prática e consequente evolução progressiva no domínio do conhecimento da assistência e do processo de enfermagem.

\section{CONCLUSĀO} que:

O presente estudo permitiu-nos concluir

Quanto à percepção dos registros:

- 96,15\% (25) dos alunos integrantes do Grupo A consideram seus registros como bom no início ao término do semestre em que cursaram a disciplina de Assistência de Enfermagem ao Adulto III.

$-77,77 \%$ (21) e $88,88 \%$ (23) dos sujeitos integrante do Grupo B constataram com bom seus registros no início e ao término do curso da disciplina de Assistência de Enfermagem ao Adulto III, respectivamente.

Quanto aos critérios de classificaçāo

-76,93\% (23) e $88,46 \%$ (23) dos sujeitos do Grupo A e $55,55 \%$ (15) e $66,66 \%$ (18) do Grupo $B$ respectivamente, no início e término da disciplina de Assistência de Enfermagem ao Adulto III apresentarain registro de enfermagem quanto ao no de sinais "compostas".

- $96,15 \%$ (26) e $100 \%$ (26) sujeitos do Grupo A e 74,08 $(20)$ e $22(81,48)$ do Grupo B apresentaram respectivamente no início e término de disciplina registros de enfermagem quanto ao estilo "claro".

- $84,62 \%$ (26) e $100 \%$ (26) sujeitos do Grupo A e 77,77 (21) e $100 \%$ (27) do Grupo B apresentaram respectivamente no início e no término de disciplina registros de enfermagem quanto à linguagem "Especializada".

- $88,46 \%$ (23) e $92,31 \%$ (24) sujeitos do Grupo A e 66,66\% (18) 81,49\% (22) do Grupo B apresentaram respectivamente no início e no término da disciplina registros de enfermagem quanto à coesão "uniforme".

- 76,93\% (20) e $15(56,70 \%)$ alunos do Grupo A 66,66 (18) e 55,55 (15) sujeitos do Grupo B apresentaram respectivamente no inicio e no término da disciplina registros de enfermagem quanto à densidade "sintéticos".

- 56,70\% (15) sujeitos do Grupo A e 15 $(66,66 \%)$ do Grupo B apresentaram respeictivamente no início do semestre registro de enfermagem quanto ao propósito do tipo dissuasivo e ao término do curso da disciplina de Assistência de Enfermagem ao Adulto III - Enf 113 os registros foram dissuasivos $55,55 \%$ (15) no Grupo B e 73,08 (19) no Grupo A persuasivos. 
- Não houve variabilidade significativa en-

tre os registros de enfermagem do Grupo A e os do Grupo B.

\section{REFERÊNCIAS BIBLIOGRÁFICAS}

1 ANGERAMI, E.L.S. et alii. Análise crítica das anotaçōes de enfermagem. Rev. Bras. Enf., Brasília, 29(4): 28-37, Out./Dez. 1976.

2 _. A composiçäo das anotaçöes de enfermagem sobo ponto de vista da equipe médica. Rev. Bras. Enf., São Paulo, 2(1): 27-31, Jan./Fev. 1982.

3 . Conceitos teóricos acerca das anotaçōes de enfermagem. Enfermagem Atual, Rio de Janeiro, 3(1): 21 -4, Jan./Fev. 1981.

4 BERLO, D. O processo de Comunicação, Rio de Janeiro; Fundo e Cultura, 1972.

5 CALDAS, N.P. et alii. Instrumentos de registro das atividades de enfermagem. Rev. Bras. Enf. Brasilia, 29(3): 92-102, Jul./Set. 1976.

6 CAR, M.C. et alii. Ensino da prescrição de en fermagem médico- cirúrgica na Escola de Enfermagem da Universidade de São Paulo. Rev. da Esc. de Enf. da USP. São Paulo, 19(2): 135-44, Ago., 1985.

7 CHACCUR, M.I.B. Análise da implementaçāo do planejamento da Assistência de Enfermagem em unidade de internação de um Hospital de Ensino. Rev. Bras. Enf. Brasília, 37(314): 218-17, Jul./Dez. 1984.

8 COSTA, S.C. da. Mensuração da qualidade dos cuidados de enfermagem: apresentação de um método para auditoria de planos de cuidados. Dissertação (Mestrado em Enfermagem) - Escola de Enfermagem Ana Neri, Universidade Federal do Rio de Janeiro, 1982.

9 CROSSETTI, M. DA G.O. Análise da prescrição de enfermagem em seu as pecto estrutural - implicações assistenciais e educacionais. Tese (Livre Docência em Enfermagem) - Escola de Enfermagem da Universidade do Estado do Rio de Janeiro, 1989.

10 CUNHA, K. de C. Análise dos registros das atividades do pessoal de enfermagem em ambulatórios de um hospital. Rev. Bras. Enf. São Paulo, 5(3): 127-30, Jul./Set., 1985.

11 DANIEL, L.F. A en fermagem plane jada. 3 ed., São Paulo: Pedagógica e Universitária, 1981,135 p.
12 DUARTE, A.D. et alii - A importancia das anotaçöes dos cuidados de enfermagem, Rev. Bras. Enf., Brasília, 29(6): 83-91, Out./Dez. 1976.

13 FAVERO, N. et alii. A importáncia da comuricação como instrumento odministrativo: especial referéncia d anotação de enfermagem. Rev. Paulista de Hospitais. São Paulo, 31(1/2): 4-7, Jan./Fev. 1983.

14 FERNANDES, R.A. et alii. Anotaçōes de enfermagem. Revista da Escola da USP. São Paulo, 15(1): 63-8, Jan./Abr. 1981.

15 FRAGA, M.N. Influência das percepçöes, observaçōes e anotações do enfermeiro sobre as açöes da equipe de saúde no atendimento ao paciente psiquiátrico. Rev. Bras. Enf. Brasilia, 33(2): 223-35, Abr./Jun. 1980.

16 HORTA, W.A. Metodologia do processo de enfermagem Rev. Bras. Enf., Brasília, 24(6) 81-95. Out./Dez. 1971.

17 LUCKESI, M.A.V. et aliix. Aplicação do processo de enfermagem no Hospital Ana Neri. Rev. Bras. Enf. Brasilia, 31(3): 141-56, Abr./Jun. 1978.

18 NÓBREGA, M.R.S. A propósito das anotaçöes de en fermagem. Enfermagem Atual. Rio de Janeiro, 2(11): 30-1, Mar./Jun. 1980.

19 PAIM, L. Problemas, prescrição e planos. Brasília: ABEn, 1978, (Cadernos Científicos ABEn, 1).

20 PARRY, J. Psicologia comunicação humana. 2 ed., São Paulo: Cultrix, 1976.

21 SANCHEZ, S. et alii. Fatores que influenciaram na implementaçâo de um modelo de assistência de enfermagem. uma proposta alternativa. Rev. Bras. Enf. Brasilia, 37(3/4): 195-204, Jul./Dez. 1984.

22 TRA VELBEE, J. Aspectos de la relacion de persona e persona; comuricacion com los pacientes. In: Intervéncion en enfermeria psiquiatrica. Colômbia: OPAS/OMS, 1979, Cap. III, V, p. 41-8, 59-93.

23 WELD, L.L. Quality control and the medical record. Medical Record News, New York, Out. 1971, p. 98-105. 